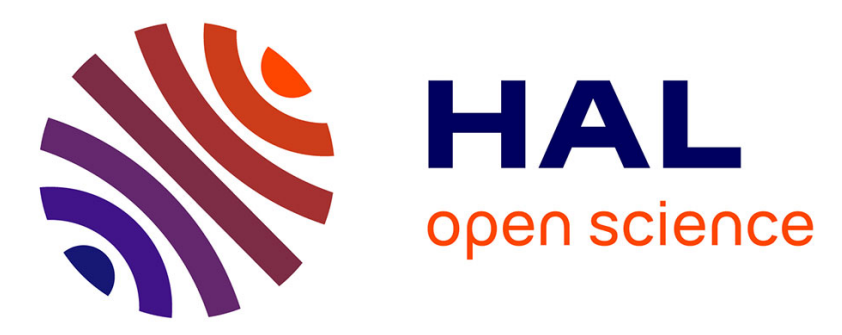

\title{
Stimulating Conversations in Residential Care Through Technology-Mediated Reminiscence
}

\author{
Francisco Ibarra, Marcos Baez, Francesca Fiore, Fabio Casati
}

\section{To cite this version:}

Francisco Ibarra, Marcos Baez, Francesca Fiore, Fabio Casati. Stimulating Conversations in Residential Care Through Technology-Mediated Reminiscence. 16th IFIP Conference on Human-Computer Interaction (INTERACT), Sep 2017, Bombay, India. pp.62-71, 10.1007/978-3-319-67687-6_5 . hal01717204

\author{
HAL Id: hal-01717204 \\ https://hal.inria.fr/hal-01717204
}

Submitted on 26 Feb 2018

HAL is a multi-disciplinary open access archive for the deposit and dissemination of scientific research documents, whether they are published or not. The documents may come from teaching and research institutions in France or abroad, or from public or private research centers.
L'archive ouverte pluridisciplinaire $\mathbf{H A L}$, est destinée au dépôt et à la diffusion de documents scientifiques de niveau recherche, publiés ou non, émanant des établissements d'enseignement et de recherche français ou étrangers, des laboratoires publics ou privés. 


\title{
Stimulating Conversations in Residential Care through Technology-mediated Reminiscence
}

\author{
Francisco Ibarra, Marcos Baez, Francesca Fiore, and Fabio Casati \\ University of Trento, Italy \\ $\{f j$. ibarracaceres, marcos.baez, francesca.fiore, fabio.casati\}@unitn.it
}

\begin{abstract}
In this paper we describe the design of a reminiscence-based social interaction tool, namely Collegamenti, that aims at stimulating conversations and a sense of mutual awareness in residential care. Unlike previous work, Collegamenti focuses on stimulating the different types of relationships that are relevant to the quality of life in residential care: interactions with primary family caregivers, contacts with the larger family, friendships with peer residents and interactions with the nursing home staff. We explore the needs and challenges of this scenario in terms of social interactions but also in terms of how to make the technology sustainable and well integrated with care practices and initiatives, and report on the findings from the qualitative studies and concept validation.
\end{abstract}

Keywords: social interactions, reminiscence, older adults, nursing homes

\section{Introduction}

Transitioning to long-term residential care demands major adjustments in the life of an older adult and his/her family [9]. In this scenario, connecting with family and peers is a key aspect contributing to adaptation, social integration, sense of belonging, and general wellbeing $[4,6,17]$. However, staying socially active can be challenging in this new environment where older adults are often placed without much choice for alternatives. Failing to remain socially engaged is known to have devastating effects on the nursing home (NH) life, contributing to feelings of loneliness, boredom, helplessness, declining mental health, reduced happiness, and increased mortality $[5,14,3]$.

Despite efforts in promoting social activities in NHs, social isolation and loneliness are still main concerns in residential care [16]. The causes include different physical, psychological, and contextual factors that influence the opportunities and motivations of older adults to interact with others.

In this paper we describe the concept development of a reminiscence-based social interaction tool, called Collegamenti, that aims at stimulating conversations in residential care.

Reminiscence is the process of recollecting past memories, a practice that is common at all ages [20] and often conducted with older adults due to its various functions and benefits. Webster [19] identifies eight particular functions: death preparation, identity, problem solving, teach and inform, conversation, 
boredom reduction, bitterness revival and intimacy maintenance. Thus, reminiscence serves an important social function in facilitating the sharing of personal memories with others, helping to create bonds between people [22].

In addition to lessons learned from existing reminiscence practices, our own preliminary surveys and visits (described later) identified a set of challenges that can be summarized in i) creating bonds and friendships among residents in NHs, and ii) facilitating and stimulating conversations with family members, especially the younger ones. We also understood that a solution is more likely to succeed if it fits into the processes and practices of the $\mathrm{NH}$ and its often overworked staff.

For these reasons, unlike previous research on the design of reminiscence applications (e.g., $[11,21,10,1])$, the goal is not only that of creating a digital archive that preserves memories or of reminiscing one's own life, but also that of using the information and media to discover and create connections among people (residents) who shared similar experiences, values and events, and to increase bonds with one's own family.

In the following we explore the challenges to the design of Collegamenti, describing the design process from the exploration of user needs and concept development to the early validations with nursing home stakeholders. From this research through design process [23] we derive lessons that contribute to the design of social interaction tools for $\mathrm{NH}$ residents.

\section{Background}

\section{$2.1 \quad$ Related Work}

Previous work on design for reminiscence and storytelling can be summarized in the following topics: facilitating usage by older adults, collecting memories, stimulating memory recall, and supporting conversations.

Using tangible interfaces is a prominent approach to facilitating the use of reminiscence solutions. Memento [21] uses scrapbooks and digital pens for memory collection and sharing, combining tangible scrapbooks that are already familiar to older adults with the benefits of online sharing. A similar setting using physical albums and digital pens - was tested in [13] with positive results in terms of engagement and social interactions. The "Reminiscence Map" [7] is another example of a digital-physical interface but with a focus on stimulating memories around places. These are great examples of how familiar interfaces can facilitate usage by older adults. However, they do not facilitate the collection of pictures or stories, and offer no support for peer interaction and discovery.

Several solutions support the collection of pictures and stories. For example, PicMemory [11] facilitates memory collection by allowing family members of all ages to collect family stories collaboratively. It also provides a multi-modal interface to facilitate contributions by older family members. PicGo [10] proposes instead a solution to iteratively collect meaningful tags from pictures during reminiscence sessions (picture capturing and browsing) with older adults with dementia. These solutions point to the importance of collaboration and gathering 
context from stories. However, they do not address the challenge of creating bonds among older adults and limit the use of tags to browsing.

Facilitating social interactions is instead at the center of solutions such as digital photo frames [8]. The CIRCA project [1] explores the use of databases of video, music and photos to prompt conversations among carers, relatives and older adults in residential settings. CaraClock [18] facilitates instead browsing of collective memories via a clock-shaped digital photo albums that can be paired to show collective memories of a family from the perspective of each member. Virtual reality has also been explored with older adults affected by dementia, with interesting results for recreating past memories, although the support for group activities remains a challenge [15].

The above solutions provide valuable insights into the design of reminiscence technology, which we take as inspiration for Collegamenti. However, a major gap is still that of supporting social integration and bonding among residents, while also accommodating to the specific needs of older adults in residential care.

\subsection{Our preliminary studies}

To investigate the nature of relationships in residential care, we visited four nursing homes in northern Italy, in the spring and summer of 2016. During the visits, we conducted observations, semi-structured interviews and focus groups. All activities were attended by at least three researchers, in order to collect different perspectives and to reduce the chance of bias.

We found out that it is hard for residents to form friendships in NHs. The staff reports that residents do not make friends. In addition to the reasons mentioned in the introduction, budget and efficiency constraints sometimes interfere with fostering relationships. For example, allocation of residents is often based on the evolution of their health condition as well as organizational efficiency needs and not on their preferences.

Family members, especially the primary family caregiver (the spouse, a sibling or a child), visit very frequently, several times per week and, in some cases, every day. Young grandchildren also come along often, with some $\mathrm{NHs}$ even providing recreational spaces to encourage the visits, while young adults visit less frequently. This is not surprising, and is line with surveys to university students, who reported a very low frequency of interactions with their grandparents because of lack of time and common topics of conversation [2].

The NH staff organizes various activities to facilitate social interactions such as volunteering, cooking, handcrafting, religious and animation activities. While this works for some residents, especially those more independent and integrated, stimulating interactions and participation is still a challenge. As reported during a focus group "At the end of the day, it is up to the ability and sensibility of the staff to identify opportunities for interaction and bringing residents closer".

Indeed an important take-home message from our preliminary studies is that there is plenty of space to improve the social interactions and the quality of relationships for people in nursing homes and their families, and to bring people together so that they can better integrate and feel part of the NH life. In 


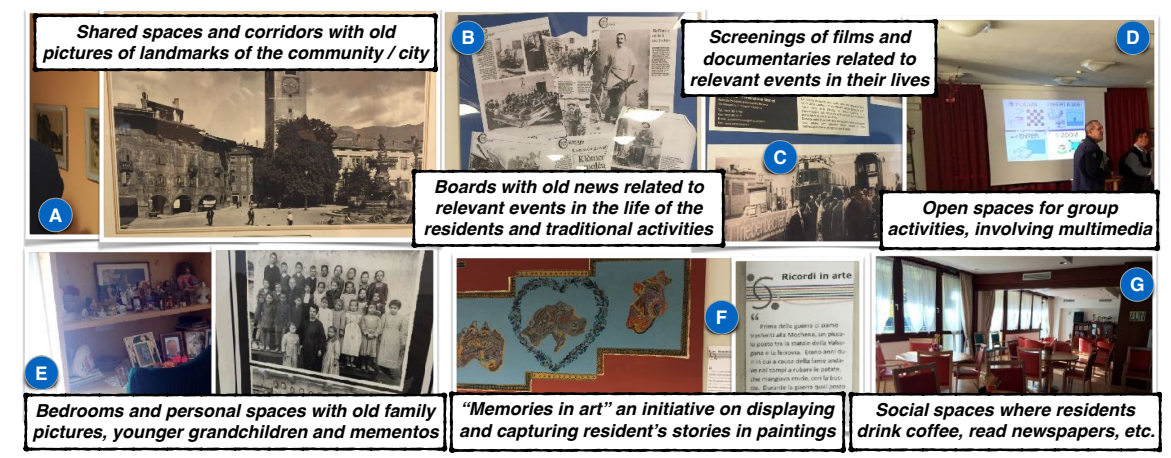

Fig. 1. Collage of pictures taken during the visits to the nursing homes.

this regard, reminiscence provides a great opportunity. Storytelling and past events are already a prominent theme in the NHs, not only as part of the reminiscence therapies for residents with dementia but as an integral part of the community as a whole:

- Corridors and shared spaces are decorated with old pictures of relevant places and news from the residents' lives (Figure 1A, 1B).

- Documentaries and films related to the residents' lives are screened as part of the animation activities (Figure 1C).

- Personal spaces feature pictures of family members, residents' important events and other mementos (Figure 1E).

- Some initiatives such as "Memories in art" from one NH, aim at sharing residents' stories with the $\mathrm{NH}$ community (Figure $1 \mathrm{~F}$ ).

- Social spaces allow for group activities as well as more intimate family interactions (Figure 1D, 1G). Some group activities rely on technology support.

The challenge is then to build on the above practices, to support the social function of the reminiscence process, to i) capture stories, taking them from the corridors to the virtual world, to involve more family members, especially younger generations; and ii) use stories to start stimulating conversations, enriching family visits, bringing people together, and creating bonds among residents.

\section{Collegamenti}

Based on our preliminary studies, we developed the concept of a reminiscencebased tool, namely Collegamenti, that aims at stimulating conversations in residential care. It does so by enabling family members and friends to digitize pictures related to the life of the older adult, to then browse them together in a process that motivates social interactions while collecting stories and relevant information about the life of the person. This information can be used later to summarize important moments in the life of the person and to identify peers 


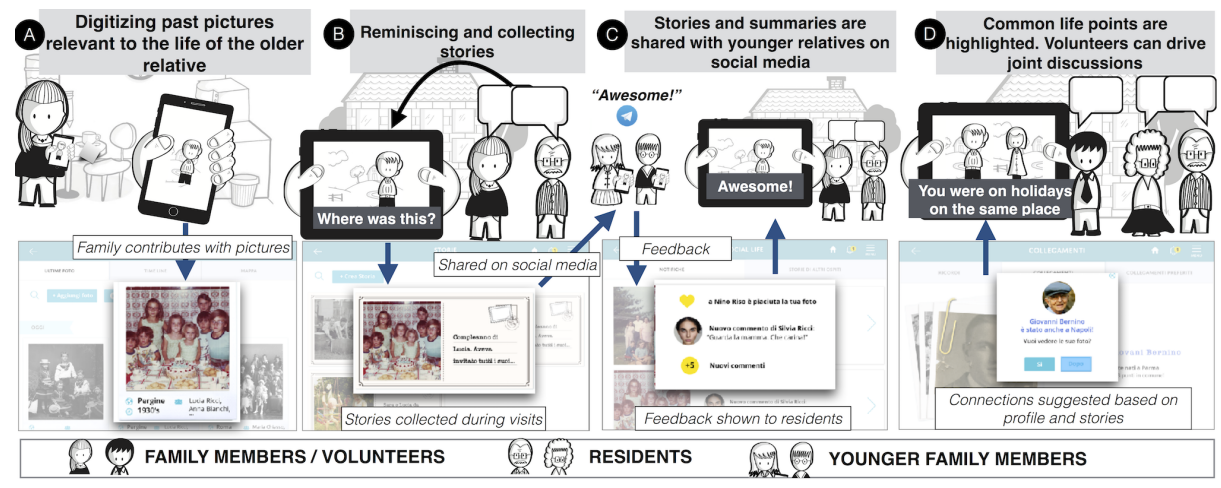

Fig. 2. Collegamenti concept and usage scenario.

sharing similar life events and stories with the purpose of making new friends or reconnecting with old ones.

We based the design and usage scenario on the limitations of frail residents (which are the large majority in $\mathrm{NHs}$ ), who are not really able to operate a tablet, making the interaction with Collegamenti assisted by family members and staff. Thus, the design allows for a multi-user interaction mode, optimized so that residents are able to see the content, while the family and staff drive the sessions. As seen in Figure 2, Collegamenti builds on four main activities:

- Digitizing pictures. Family members contribute by adding pictures and tags (place, date, people in the picture), and can even collaborate to collect relevant tags on each other's pictures. This alone allows the family to build an archive of relevant moments. Once digitized, pictures are automatically added to the resident's account, becoming available to all collaborators.

- Reminiscing and collecting stories. During the visits, family members (or staff) engage in reminiscence sessions with the residents. Digitized pictures are used as prompts to engage in meaningful interactions and to collect stories. At this phase, tags can also be refined with the help of the resident. The idea is to make visits more interesting, not only to collect information. Therefore, pictures and stories created can be revisited at any time, becoming a trigger for memories and conversation.

- Engaging in online interactions. The stories collected can be shared with the NH community and family members (on social media), which could derive in additional interactions, during visits and also online with the larger family. Residents (with the help of a facilitator) can access the feedback on his/her shared stories. Feedback from social media is captured and displayed in a format that facilitates the consumption and response. In the same way, residents can access pictures and stories from other residents (friends) that could lead to face-to-face interactions. Thus, by enabling online interactions with family and peers we do not only aim at opening a communication channel, but at stimulating conversations. 
- Connecting with other residents. The stories and tags collected are also used to find potential friends. Building on the homophily effect, which suggests that similarities among people lead to creating ties [12], Collegamenti would suggest friends based on common life events and their likelihood to create bonds. Suggestions include reasons for the connection, that aim at i) introducing the other person, and ii) highlighting the common aspects (e.g., "You and Gianni were born in Parma").

The above process relies heavily on the cooperation and interest of the $\mathrm{NH}$ staff and the primary family caregiver (on average 65 years old). This poses several challenges since we need to understand if such a solution is feasible in the NH context. Aspects that deal with the interaction design are not addressed in this paper, although the reader can refer to our low-fidelity prototype ${ }^{1}$ for a close experience.

\section{Methods}

We conducted interviews with relatives of $\mathrm{NH}$ residents and members of the animation staff, and a work table with additional NH actors, aiming at:

- Assessing whether the concept and use of Collegamenti fits into current $\mathrm{NH}$ practices and activities performed by both relatives and staff

- Determining whether relatives and staff would be interested and able to perform the four main activities of Collegamenti (see Figure 2)

Semi-structured interviews were conducted by two researchers. We contacted one nursing home asking to interview relatives, and at least two members of the animation staff. The NH recruited both relatives and staff. We interviewed five relatives, each of a different resident, about Collegamenti's main activities (see Figure 2) while, one volunteer and the coordinator of animation were interviewed on their current tasks and reminiscence related activities, and on the fitness of Collegamenti in the context of their work. Both interviews were complemented with a description and a storyboard of Collegamenti.

The work table was led by the same two researchers. Eighteen NHs in northern Italy were contacted to participate, among those willing to participate we chose randomly eight people, but ensured an equal number of men and women, and that no two participants belonged to the same NH. The table was attended by three NH directors, four coordinators (one of animation), and one relative. Personas built from our preliminary studies were presented along with a storyboard and a prototype. Participants were asked to write down challenges in the use of Collegamenti and reasons for not using it, as well as reasons for being used and liked. Then, the four main activities were presented and participants were asked to write challenges for their realization and current similar practices.

\footnotetext{
${ }^{1}$ http://invis.io/USB4KFP7N
} 


\section{Results}

We have aggregated the feedback obtained from both the interviews and the work table, which were in a high level of agreement. Next we present the $\mathrm{NH}$ practices, and opportunities and challenges for Collegamenti's adoption.

\subsection{Collegamenti in nursing home practices}

In some ways some of Collegamenti's activities are already conducted in NHs.

Digitizing pictures. Some residents take their old pictures to the NH, and old pictures have already been used in past activities ("I've brought photos from home for the story book"). Moreover, the animation staff is familiar with digitizing pictures ("now we take pictures of old photos") and some relatives would also be willing to help ("I could scan the pictures... and send them by e-mail").

Reminiscence and story collection. We have identified many comparable activities, such as making the biography on entry to the NH, collecting residents' life stories and interests, and the existence of a $\mathrm{NH}$ newspaper about residents' stories and past (such as old traditions, or their old craft). It is worth mentioning that $\mathrm{NH}$ stakeholders value such activities ("There is a therapeutic, rehabilitation aspect to it that is very useful"), and note that they can help to increase residents self-worth and self-esteem. Moreover, participants observe that the involvement of relatives (in this case as facilitators during reminiscence sessions) would be beneficial since it increases the interactions between relatives and residents, and increases the trust towards the nursing home ("Involving relatives improves the relation with the $\mathrm{NH}$ because they feel part of the care").

Sharing in social media is also done using NH websites or Facebook pages. Although content is mostly about current events, it was a pleasant surprise to find out that residents already have some sort of online presence. However, despite other means being used for online sharing ("There is a digital version of the NH newspaper", "We share pictures in Whatsapp"), for residents most sharing still happens offline. The NH newspaper is printed and shared with relatives and within the $\mathrm{NH}$ community, and the collection of life stories is sometimes conducted as a group activity. Still, this is encouraging since it indicates a good disposition towards sharing.

Connecting with other residents. Residents can occasionally find out about common points ("Sometimes we find common points while talking all together", "[residents] already share -common points- autonomously or during the life stories activities"). Nonetheless, participants mentioned that these similarities are quite significant to generate interactions and rapport between residents ("Common interests are the spark to create a bond").

\subsection{Challenges for adoption}

Despite the similarities between Collegamenti's main activities and current practices in NHs, there are challenges to $\mathrm{NH}$ adoption of Collegamenti as a tool. 
Workload of facilitators. The main activities of Collegamenti can be time and effort consuming, and it is well known that the NH staff runs a tight work schedule. Clearly, residents will need support to use Collegamenti, and no one actor can support all the activities. Therefore, participants recognize the importance of collaboration between the residents' relatives and the NH staff (" $A$ strong involvement of the relatives is needed").

Privacy management. Participants noted that some of the information collected from pictures and stories can be considered as personal by residents ("Residents are still very reserved. I see this more as a family thing"). Participants emphasized that Collegamenti should allow to control which pictures and stories are available for sharing, as well as whom to share with. This becomes particularly important if sharing is automatic (e.g. on social media).

Residents cognitive skills. Despite the assistance of facilitators, not all residents would be able to use Collegamenti. Participants have pointed out that a part of the residents might not be able to remember facts about the picture ("Only a small percentage of residents would be able to remember all this"). Participants have highlighted the importance of identifying able and interested residents (as well as relatives who would act as facilitators).

\section{Discussion and future work}

The preliminary studies, along with the literature review, stress the need for promoting social interactions in residential care. This is a complex and challenging problem, requiring the support and collaboration of the care network, since most residents are limited in their ability to seek opportunities on their own.

The studies reported in this paper point to the feasibility of using reminiscencebased technology as a sustainable instrument for promoting social interactions in residential care. The proposed concept of Collegamenti has received positive feedback in terms of i) supporting current $\mathrm{NH}$ practices and activities from staff and family members, ii) providing more opportunities, for interaction between the residents and relatives, and for collaboration between staff and relatives, and iii) expanding the reach of reminiscence-based activities, by sharing in online channels to reach younger audiences, and evidencing common life points between residents. However, these results should be interpreted within the studied cultural context. The challenges reported also indicate the need for additional features and further consideration to the process.

As for ongoing and future work, we are iterating on the design of the application, taking in consideration the aforementioned challenges, and planning experience prototyping sessions with residents and family members.

Acknowledgements. This project has received funding from the EU Horizon 2020 research and innovation programme under the Marie Skodowska-Curie grant agreement No 690962. This work was also supported by the "Collegamenti" project funded by the Province of Trento (l.p. n.6-December 13rd 1999). 


\section{References}

1. Astell, A., Alm, N., Gowans, G., Ellis, M., Dye, R., Campbell, J., Vaughan, P.: Working with people with dementia to develop technology: The circa and living in the moment projects. PSIGE Newsletter 64 (2009)

2. Baez, M., Dalpiaz, C., Hoxha, F., Tovo, A., Caforio, V., Casati, F.: Personalized persuasion for social interactions in nursing homes. In: Persuasive Technologies 2016 (2016)

3. Berkman, L.F., Syme, S.L.: Social networks, host resistance, and mortality: a nineyear follow-up study of alameda county residents. American journal of Epidemiology 109(2), 186-204 (1979)

4. Bradshaw, S.A., Playford, E.D., Riazi, A.: Living well in care homes: a systematic review of qualitative studies. Age and ageing p. afs069 (2012)

5. Brummett, B.H., Barefoot, J.C., Siegler, I.C., Clapp-Channing, N.E., Lytle, B.L., Bosworth, H.B., Williams Jr, R.B., Mark, D.B.: Characteristics of socially isolated patients with coronary artery disease who are at elevated risk for mortality. Psychosomatic Medicine 63(2), 267-272 (2001)

6. Friedemann, M.L., Montgomery, R.J., Maiberger, B., Smith, A.A.: Family involvement in the nursing home: Family-oriented practices and staff-family relationships. Research in Nursing \& Health 20(6), 527-537 (1997)

7. Huldtgren, A., Vormann, A., Geiger, C.: Reminiscence map-insights to design for people with dementia from a tangible prototype. In: ICT4AgeingWell. pp. 233-242 (2015)

8. Kim, J., Zimmerman, J.: Cherish: smart digital photo frames for sharing social narratives at home. In: CHI'06 Extended Abstracts on Human Factors in Computing Systems. pp. 953-958. ACM (2006)

9. Lee, D.T., Woo, J., Mackenzie, A.E.: A review of older peoples experiences with residential care placement. Journal of advanced nursing 37(1), 19-27 (2002)

10. Lee, H.C., Cheng, Y.F., Cho, S.Y., Tang, H.H., Hsu, J., Chen, C.H.: Picgo: designing reminiscence and storytelling for the elderly with photo annotation. In: Proceedings of the 2014 companion publication on Designing interactive systems. pp. 9-12. ACM (2014)

11. Lee, H.C., Hsu, J.Y.j.: Picmemory: Enriching intergenerational family interaction and memory collection. In: Proceedings of the 2016 CHI Conference Extended Abstracts on Human Factors in Computing Systems. pp. 3715-3718. ACM (2016)

12. McPherson, M., Smith-Lovin, L., Cook, J.M.: Birds of a feather: Homophily in social networks. Annual review of sociology 27(1), 415-444 (2001)

13. Piper, A.M., Weibel, N., Hollan, J.: Audio-enhanced paper photos: encouraging social interaction at age 105. In: Proceedings of the 2013 conference on Computer supported cooperative work. pp. 215-224. ACM (2013)

14. Seeman, T.E., Berkman, L.F., Blazer, D., Rowe, J.W.: Social ties and support and neuroendocrine function: the macarthur studies of successful aging. Annals of Behavioral Medicine (1994)

15. Siriaraya, P., Ang, C.S.: Recreating living experiences from past memories through virtual worlds for people with dementia. In: Proceedings of the 32nd annual ACM conference on Human factors in computing systems. pp. 3977-3986. ACM (2014)

16. Theurer, K., Mortenson, W.B., Stone, R., Suto, M., Timonen, V., Rozanova, J.: The need for a social revolution in residential care. Journal of aging studies 35, 201-210 (2015) 
17. Thomas, W.H.: Life worth living: How someone you love can still enjoy life in a nursing home: The Eden Alternative in action. Publisher: VanderWyk\&Burnham (1996)

18. Uriu, D., Shiratori, N., Hashimoto, S., Ishibashi, S., Okude, N.: Caraclock: an interactive photo viewer designed for family memories. In: CHI'09 Extended Abstracts on Human Factors in Computing Systems. pp. 3205-3210. ACM (2009)

19. Webster, J.D.: Construction and validation of the reminiscence functions scale. Journal of Gerontology 48(5), P256-P262 (1993)

20. Webster, J.D., Gould, O.: Reminiscence and vivid personal memories across adulthood. The International Journal of Aging and Human Development 64(2), 149-170 (2007)

21. West, D., Quigley, A., Kay, J.: Memento: a digital-physical scrapbook for memory sharing. Personal and Ubiquitous Computing 11(4), 313-328 (2007)

22. Westerhof, G.J., Bohlmeijer, E.T.: Celebrating fifty years of research and applications in reminiscence and life review: State of the art and new directions. Journal of Aging studies 29, 107-114 (2014)

23. Zimmerman, J., Forlizzi, J., Evenson, S.: Research through design as a method for interaction design research in hci. In: Proceedings of the SIGCHI conference on Human factors in computing systems. pp. 493-502. ACM (2007) 